\title{
Commentary: From the aorta to the femoral artery and back again: An iconic round trip
}

\author{
Kareem Bedeir, MD, Tsuyoshi Kaneko, MD, and Sary Aranki, MD
}

\author{
From the Division of Cardiac Surgery, Brigham and Women's Hospital, Harvard Medical School, Boston Mass. \\ Disclosures: T.K. is a speaker and proctor for Edwards, Medtronic, and Abbott. All other authors have nothing to \\ disclose with regard to commercial support. \\ Received for publication Aug 17, 2018; accepted for publication Aug 20, 2018; available ahead of print Oct 6, \\ 2018. \\ Address for reprints: Sary Aranki, MD, Division of Cardiac Surgery, Brigham and Women's Hospital, 75 Francis \\ St, Boston, MA 02115 (E-mail: saranki@partners.org). \\ J Thorac Cardiovasc Surg 2019;157:1402-3 \\ $0022-5223 / \$ 36.00$ \\ Copyright (c) 2018 by The American Association for Thoracic Surgery \\ https://doi.org/10.1016/j.jtcvs.2018.08.038
}

Porterie and colleagues ${ }^{1}$ report on 203 patients who underwent transaortic access transcatheter aortic valve implantation (TAVI) via an upper ministernotomy. The cohort includes patients with a hostile ileofemoral artery anatomy and a mean Society of Thoracic Surgeons score of 8.9 (standard deviation, 5.4). Over the period of approximately 5 years, changes have been made; 4 different valves have been used, and the latter $73 \%$ of cases underwent an innominate artery (IA) access as opposed to the ascending aorta (AAo), which correlated with a shorter length of stay. Major clinical outcomes reported are within the expected range with favorable hemodynamic outcomes with no cases of more than mild paravalvular leaks.

The authors suggest that the shorter length of stay with IA access is related to the absence of pericardiotomy and less invasiveness of the procedure. Although this may be the case given the lower transfusions required with IA access, this subset of patients in their cohort had a significantly lower average Society of Thoracic Surgeons score, lower New York Heart Association class, and less prior hospitalization, so this conclusion may be biased. Another interesting statistic in this cohort is the survival over the study period. They report a periprocedural mortality of $1.5 \%$, a 30 -day mortality of $5.3 \%$, a 1 -year mortality of $15 \%$, and an overall mortality of $40 \%$. This striking progression highlights how procedural success may represent only a small step toward the well-being of these patients with high-risk aortic stenosis from a vantage point. This becomes more of an ethical issue; the counseling of patients with preTAVI must set a realistic goal whether an enhanced quality of life or survival is what they are trying to gain. It would have been interesting to know the predictors of late mortality and whether even mild paravalvular leaks had a significant impact on late results.

The Transcatheter Valve Therapy registry reports that transfemoral access increased from $47 \%$ of cases in 2013 to $94 \%$ of cases by the end of $2017 .^{2}$ In the study by Porterie and colleagues, ${ }^{1} 20 \%$ of all patients who underwent TAVI will be (if any).

\section{References}

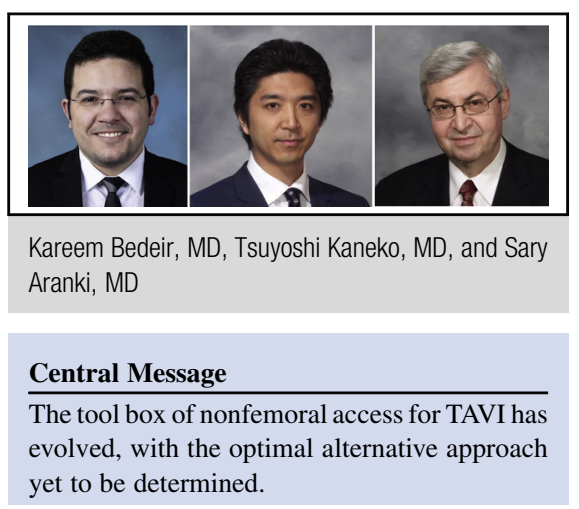

See Article page 1393.

received AAo access, which is a proportion that is easily predicted to decrease in the future. In their strategy selection, the subclavian/axillary (SC/Ax) access has been used in $1.3 \%$ versus AAo/IA access in $20 \%$, and the former being reserved for contraindications to AAo/IA. We would be curious to see the comparison between the 2 groups, as with the transfemoral group during the same period.

With the smaller devices available, peripheral access such as SC/Ax or the carotid approach is becoming more popular as shown in the Transcatheter Valve Therapy registry data. The SC/Ax access is a well-established, lessinvasive approach with reported consistent good outcomes. ${ }^{3,4}$ We believe that the peripheral approach will be the future of alternative access for TAVI, although there will always be a patient who will need AAo access as a last resort.

The gold standard treatment of aortic stenosis has been surgical AVR using the ascending aortic approach on cardiopulmonary bypass. This was revolutionized by offpump AVR, that is, TAVI. The initial approaches for TAVI in the first large clinical trials were retrograde (transfemoral) or antegrade (transapical). We are taking the iconic round trip back to the aorta with the transaortic approach. It remains to be seen what the next destination

1. Porterie J, Mayeur N, Lhermusier T, Dumonteil N, Chollet T, Lairez O, Marcheix B. Aortic and innominate routes for transcatheter aortic valve implantation. J Thorac Cardiovasc Surg. 2019;157:1393-401.e7.

2. Grover FL, Vemulapalli S, Carroll JD, Edwards FH, Mack MJ, Thourani VH, et al. 2016 annual report of The Society of Thoracic Surgeons/American College of Cardiology transcatheter valve therapy registry. J Am Coll Cardiol. 2017;69:1215-30. 
3. Gleason TG, Schindler JT, Hagberg RC, Deeb GM, Adams DH, Conte JV, et al. Subclavian/axillary access for self-expanding transcatheter aortic valve replacement renders equivalent outcomes as transfemoral. Ann Thorac Surg. 2018;105: 477-83.
4. Ramlawi B, Bedeir K, Barker C, Lin CH, Kleiman N, Reardon M. Direc aortic and subclavian access for transcatheter aortic valve replacement: decision making and technique. J Thorac Cardiovasc Surg. 2014;148: $353-6$. 